\title{
O desempenho das mulheres nas eleições legislativas de 2010 no Rio Grande do Sul
}

Women performance in the legislative assembly elections of 2010 in Rio Grande do Sul

A presença das mulheres nas eleições de 2010 foi antecedida de uma preparação bastante cuidadosa, se fizermos uma comparação com a série histórica de eleições. Houve esforços diferenciados para mudar o quadro de escassa presença feminina nos cargos executivos e legislativos ao longo da história republicana. ONGs, núcleos de pesquisa sobre a mulher localizados em universidades, a própria Secretaria de Políticas para as Mulheres (SPM) promoveram encontros e elaboraram materiais de divulgação com o objetivo de fomentar discussão com mulheres ligadas aos partidos políticos e aos movimentos sociais sobre a entrada da mulher na vida política nacional. Além disso, foram criados sites altamente qualificados, como o Observatório Brasil de Igualdade de Gênero, da secretaria, e, fora do âmbito governamental, o Mulheres no Poder ${ }^{1}$.

No ano de 2009, por força da mobilização das mulheres, houve três significativas mudanças na condição das candidatas com a promulgação da Lei n. 12.034. Essa legislação, aprovada em 2009, norteou o pleito do ano seguinte e substituiu a Lei Eleitoral n. 9.504/97. Entre as suas alterações, destacam-se: a

É doutora em Ciência Política e professora do Departamento de História da Universidade Federal do Rio Grande do Sul (Porto Alegre, RS). E-mail: celirjp@gmail.com.

* É doutora em Ciência Política e professora do Departamento de Ciência Política da Universidade Federal do Rio Grande do Sul (Porto Alegre, RS).E-mail: marialuciamor@ig.com.br.

*** É doutora em Ciência Política e professora do Departamento de Sociologia e Política da Universidade Federal de Pelotas (Pelotas, RS). E-mail: rosangelaschulz@gmail.com.

Os endereços dos sites são: www.observatóriodegenero.gov.br e www.mulheresnopoder.com.br. 
garantia às mulheres de $5 \%$ do fundo partidário para a criação e manutenção de programas de promoção e difusão da participação feminina; a presença de no mínimo 30\% de mulheres nas listas eleitorais dos partidos; e, por fim, a reserva de $10 \%$ do tempo de propaganda eleitoral às candidatas mulheres ${ }^{2}$. Tais medidas geraram expectativas de avanço não só no número de candidatas como no de mulheres eleitas.

Se há fortes indicações de que as políticas e ações do movimento feminista adotadas no Brasil estão na direção correta, os resultados concretos desse conjunto de medidas é alarmante, particularmente quando analisados os dados das últimas eleições. Havia um otimismo dos pesquisadores do tema e dos militantes sobre a ampliação da presença das mulheres nessa campanha ao Legislativo federal e aos legislativos estaduais, fruto dos esforços promovidos nos últimos anos e do lançamento de duas fortes candidaturas femininas à Presidência da República. Entretanto, os resultados eleitorais de 2010 não confirmaram as expectativas positivas: o que se viu foi uma diminuição no número de eleitas tanto para a Câmara dos Deputados como para as Assembleias Legislativas. Os números revelam um quadro claro do cenário eleitoral para as mulheres no Brasil: em 2006 foram eleitas 45 deputadas federais e 10 senadoras, isto é, 8,8\% e 12,3\% nas respectivas casas legislativas ${ }^{3}$. Essa baixa representação feminina no Congresso Nacional coloca o Brasil na $106^{\circ}$ posição no ranking mundial em participação de mulheres no Parlamento ${ }^{4}$.

Este artigo tem como propósito contribuir para o entendimento do precário desempenho das mulheres nas eleições legislativas no Brasil, a partir de um estudo da performance das candidatas à deputação estadual e federal no estado do Rio Grande do Sul. Temos ciência de que o estudo de um único estado tem limitações e, por isso, generalizações a partir dele devem ser feitas com muita parcimônia. Mas, como o estado gaúcho não foi uma exceção em seu comportamento eleitoral no que diz respeito às candidatas mulheres, o estudo traz à discussão questões que colaboram para um melhor entendimento do desempenho eleitoral da mulher nas eleições no Brasil.

\footnotetext{
A lei n. 12.034 foi aprovada em 09 de julho de 2009 e normatizou o pleito de 2010.

Em 2009, a bancada feminina havia diminuído para 43 deputadas federais. Essa movimentação, para mais ou para menos, é corriqueira ao longo de uma legislatura, pois as representantes podem assumir outros cargos no Executivo, tanto federal como estadual ou municipal.

A posição brasileira no ranking mundial é apontada pela União Interparlamentar, órgão vinculado à ONU. Fonte: www.ipu.org.
} 
É significativa a produção na área de ciência política sobre a participação da mulher no Brasil, mormente pela distância que existe entre a presença da mulher nas áreas do trabalho e da educação e sua ausência como governadoras, prefeitas e, principalmente, como deputadas federais, deputadas estaduais e vereadoras, apesar da política específica de incentivo. No ano de 2010, o mapa político-eleitoral brasileiro indicava que havia 498 prefeitas $(9,1 \%)$, e três mulheres $(11,1 \%)$ à frente dos Governos estaduais. No âmbito do Legislativo, para onde as ações afirmativas são direcionadas, tínhamos $12 \%$ de vereadoras e 138 deputadas estaduais ${ }^{5}$.

A política de cotas, por meio da legislação específica, sofreu ao longo dos dez anos modificações favoráveis para as mulheres. Seus efeitos têm sido largamente discutidos, como no trabalho de Clara Araújo, que, ainda no primeiro momento da política de cotas, indica que os dados permitem:

Observar um ligeiro descrédito no universo de candidatas entre 1990 e 1994, que passa de 6,39\% para 6,15\%. Mas entre 1994 e 1998 ocorre uma elevação significativa do percentual de mulheres entre os concorrentes, que passa de $6,15 \%$ a $10,35 \%$. Tal elevação pode indubitavelmente ser lida como um efeito direto das cotas, embora estas não tenham chegado a atingir metade da meta mínima estabelecida, que em 1998 foi de 25\%. De todo modo, pela primeira vez as candidaturas para a Câmara Federal alcançaram a marca dos dois dígitos (Araújo, 2001, p. 234-5).

Os dados de Araújo apontam para uma mudança paulatina da condição de quase total exclusão da mulher:

Embora os dados disponíveis não permitam conclusões definitivas, os resultados obtidos até o momento não apontam para um balanço muito favorável. Em termos de alterações nas candidaturas o balanço é parcialmente positivo, pois elevou razoavelmente o universo de candidatas. Contudo, em termos de impacto sobre os eleitos, os resultados são inócuos. E as avaliações necessitam considerar isto. Entre fatores que também interferem no processo e determinam resultados diferenciados, mereceram destaque o tipo de sistema eleitoral e mais especificamente de lista eleitoral, a cultura política, além das características da lei de cotas aprovada no país, que tendem a limitar a sua eficácia. Diante disto, que cenários possíveis se delineiam à frente? (Araújo, 2001, p. 246-7).

Em 1.631 municípios brasileiros, dos 5.484 cidades existentes, nenhuma mulher elegeu-se vereadora. Já para as 27 Assembleias Legislativas a representação feminina oscila entre duas e treze eleitas. Fonte:TSE. 
Examinando o resultado eleitoral das candidatas em 2010, as ponderações de Araújo continuam pertinentes após mais de uma década ${ }^{6}$. Se a lei que garante cotas é uma medida necessária, entretanto, não é suficiente para mudar o quadro. Miguel e Biroli avançam nessa reflexão.

A sub-representação das mulheres na esfera política é, hoje, entendida como um problema. Mas as explicações para essa discrepância específica entre o universo dos eleitores e o universo dos eleitos ou dos que ocupam outras posições que lhes conferem poder variam, dando destaque para diferentes aspectos das relações de gênero. Não se trata apenas de uma questão de ênfase. Pode-se considerar que o tratamento dado ao problema mais amplo dos limites das democracias concorrenciais contemporâneas e do ideário liberal que está em sua base é um dos divisores entre as abordagens. As explicações dadas a um fenômeno específico, a sub-representação feminina, vinculam-se ao entendimento do que deve ser alvo de crítica e objeto de transformações, quando se constata que as promessas de inclusão universal não são cumpridas e que há padrões de concentração de poder que se reproduzem nas democracias existentes (Miguel e Biroli, 2010, p. 653-4).

As questões levantadas por Miguel e Biroli chamam a atenção para um problema central: a sub-representação das mulheres como efeito do próprio pacto político liberal (democracia representativa) que rege a democracia brasileira. Nesse sentido, põe em xeque o princípio da universalidade do sujeito como capaz de dar conta da representação de grupos repetidamente excluídos. Esse é o caminho seguido por significativa parcela da literatura internacional, tanto ao tratar especificamente da questão da mulher quanto ao expandir o tema para o conjunto de sujeitos excluídos, como negros, populações nativas, migrantes e pobres em geral ${ }^{7}$.

Levando em consideração o desempenho das candidatas no estado do Rio Grande do Sul no pleito de 2010, nosso estudo busca analisar a problemática da mulher na política a partir de outro ângulo: quem são as mulheres que ganham? Quais são as suas trajetórias? Enfim, por que foram vitoriosas? Dessa forma, nossa pesquisa fez perguntas distintas daquelas levantadas pelos estudos que se dedicam a explicar o pífio resultado eleitoral das mulheres e por que elas perdem as eleições. O artigo está divido em duas partes: na

Para o debate sobre a sub-representação feminina, conferir: Miguel (2000, 2001); Araújo (2001, 2005, 2009); Avelar (2001); Alvares (2004).

Sobre essa temática conferir os textos de Fraser, 2001 e 2003. 
primeira apresentaremos uma visão geral das candidaturas femininas no Brasil; na segunda, analisaremos em detalhes o desempenho das candidatas do Rio Grande do Sul à Assembleia Legislativa e à Câmara dos Deputados.

\section{Para entender a questão}

As eleições gerais no Brasil envolvem um número muito grande de candidatos, resultado da atual legislação eleitoral que permite que cada partido apresente 1,5 candidatos para cada cadeira disputada nas eleições proporcionais ${ }^{8}$. Nas últimas eleições, 21.696 candidatos se apresentaram para os cargos do Executivo e do Legislativo em todo o país, distribuídos conforme a tabela a seguir?:

Tabela 1. Eleições 2010/Brasil: distribuição de candidatos x cargo x gênero

\begin{tabular}{c|c|c|c|c|c|c}
\hline \multirow{2}{*}{ cargo } & \multicolumn{2}{|c|}{ totais } & \multicolumn{2}{c|}{ homens } & \multicolumn{2}{c}{ mulheres } \\
\cline { 2 - 7 } & $\mathrm{n}$ & $\%$ & $\mathrm{n}$ & $\%$ & $\mathrm{n}$ & $\%$ \\
\hline presidente & 10 & $100 \%$ & 8 & $80 \%$ & 2 & $20 \%$ \\
\hline governadores & 153 & $100 \%$ & 136 & $88,9 \%$ & 17 & $11,1 \%$ \\
\hline senadores & 242 & $100 \%$ & 214 & $88,4 \%$ & 28 & $11,6 \%$ \\
\hline deputado federal & 6.039 & $100 \%$ & 4.693 & $77,7 \%$ & 1.346 & $22,3 \%$ \\
\hline deputado estadual & 15.252 & $100 \%$ & 11.786 & $77,3 \%$ & 3.466 & $22,7 \%$ \\
\hline
\end{tabular}

Fonte: TSE.

A tabela acima permite visualizar dados relevantes, mas, antes, deve-se examinar sua primeira linha, uma vez que o número bruto não revela a realidade eleitoral, pois dos 10 candidatos à Presidência da República, apenas três tinham robustez suficiente para concorrerem ao cargo; os demais pertenciam a partidos muito pequenos e sem representatividade. Dessas três fortes candidaturas, duas eram mulheres: Dilma Rousseff e Marina Silva, ambas com carreiras públicas muito destacadas e ex-ministras do governo Lula.

\footnotetext{
8 A legislação eleitoral brasileira prevê que as coligações partidárias podem lançar candidatos na razão de $2 x$ o número de vagas em disputa, isso para bancadas de até 20 deputados federais. Quando as bancadas são maiores, as coligações podem apresentar até duas vezes e meia o número de vagas que estão sendo disputadas. O sistema eleitoral brasileiro é abordado por Nicolau $(2006,2007)$.

9 Esse dado pode ter pequena variação dependendo da fonte. Neste artigo usamos como fonte dos dados nacionais a página do Tribunal Superior Eleitoral (TSE) e, para os dados do Rio Grande do Sul, a Ata de Finalização do Tribunal Regional Eleitoral (TRE/RS).
} 
Se tivemos, por um lado, essa surpreendente presença de mulheres para o cargo de presidente da República, por outro, é igualmente surpreendente o reduzido número de candidatas aos Governos estaduais e ao Senado. Embora a lógica seja diferente para eleições majoritárias e proporcionais, a comparação é informativa: os índices de candidaturas à deputação estadual e federal foram o dobro em relação ao das concorrentes ao Senado e aos Governos estaduais. Mesmo longe de atingir os 30\% requeridos pela lei, esse número deve ser a ela atribuído, especialmente comparando-se com o ano de 1998, quando esse índice passou a vigorar, pois fora de apenas 6,15\% o percentual de candidatas à Câmara Federal.

No entanto, como demonstra a tabela abaixo, o aumento nas candidaturas femininas não se refletiu no número de eleitas. Entre os motivos para isso identificamos que os partidos fazem investimentos distintos quando as mulheres concorrem para vaga majoritária e quando disputam eleições proporcionais. Já sabemos que fortes candidaturas (de homens ou mulheres) ao Executivo geram efeitos positivos sobre os resultados para o Legislativo. Entretanto, com os dados de que dispomos, não podemos estabelecer uma direta correlação entre a eleição de uma mulher para um cargo majoritário e o seu impacto na formação de uma bancada feminina no Parlamento.

Tabela 2. Eleições 2010/Brasil: resultado das eleições x cargo x gênero

\begin{tabular}{c|c|c|c|c|c|c}
\hline \multirow{2}{*}{ cargo } & \multicolumn{2}{|c|}{ totais } & \multicolumn{2}{c|}{ homens } & \multicolumn{2}{c}{ mulheres } \\
\cline { 2 - 7 } & $\mathrm{n}$ & $\%$ & $\mathrm{n}$ & $\%$ & $\mathrm{n}$ & $\%$ \\
\hline presidência $^{*}$ & 1 & $100 \%$ & 0 & 0 & 1 & $100 \%$ \\
\hline governadores $^{*}$ & 27 & $100 \%$ & 25 & $92,6 \%$ & 2 & $7,4 \%$ \\
\hline senadores $^{*}$ & 54 & $100 \%$ & 47 & $87 \%$ & 7 & $13 \%$ \\
\hline deputado federal $_{\text {deputado estadual }}$ & 513 & $100 \%$ & 469 & $91,4 \%$ & 45 & $8,8 \%$ \\
\hline & 1.060 & $100 \%$ & 922 & $87 \%$ & 138 & $13 \%$ \\
\hline
\end{tabular}

Fonte: TSE.

*As duas governadoras eleitas em 2010 foram: Roseana Sarney (PMDB), pelo Maranhão, e Rosalba Ciarlini (DEM), pelo Rio Grande do Norte.

"* Em 2010 estavam sendo renovados 2/3 das vagas do Senado, por isso 54 cadeiras em disputa. As sete mulheres (13\%) que se elegeram nesse pleito foram: Gleisi Hoffmann (PT/PR), Angela Portela (PT/RR), Marta Suplicy (PT/ SP), Lúcia Costa (PMDB/GO), Lídice da Mata (PSB/BA), Ana Amélia Lemos (PP/RS) e Vanessa Grazziotin (PCdoB/AM). Fonte: TSE. 
Além do pouco êxito das mulheres, a tabela permite avançar o exame do desempenho das candidatas. Comparando esses dados com os da Tabela 1 verifica-se que não há correspondência entre a proporção de candidatas e de eleitas, o que nos possibilita levantar duas hipóteses: a primeira é que o eleitorado brasileiro parece não ter resistência a votar em mulheres, dada a significativa votação em candidatas à Presidência e ao Senado, e em algumas candidatas à deputação federal e estadual. A segunda é que a expressiva votação em mulheres tem se limitado a um pequeno número delas; no caso das eleições proporcionais, a votação tem se concentrado naquelas que possuem maior capital político acumulado na trajetória político-partidária, o que inclui mandatos eletivos anteriores, visibilidade e investimento financeiro na campanha, enquanto um número significativo de candidatas apenas figura nas listas para tentar completar o índice requerido por lei. Os resultados eleitorais do estado permitem avançarmos na compreensão das características da participação das mulheres nessas eleições. Antes de entrar especificamente na questão das candidatas ao Legislativo no Rio Grande do Sul, vale observar os resultados do primeiro e segundo turnos para a Presidência da República no estado.

Tabela 3. Eleições 2010: resultado da eleição presidencial no RS

\begin{tabular}{c|c|c}
\hline \multicolumn{3}{|c|}{$1^{\circ}$ turno } \\
\hline candidato & partido & $\%$ \\
\hline Dilma & PT & 46,95 \\
\hline Serra & PSDB & 40,59 \\
\hline Marina & PV & 11,33 \\
\hline outros & - & 1,13 \\
\hline & $2^{\circ}$ turno & $\%$ \\
\hline candidato & partido & 49,06 \\
\hline Dilma & PT & 50,94 \\
\hline Serra & PSDB &
\end{tabular}

Fonte: TSE.

Os resultados das eleições presidenciais parecem evidenciar que o fator gênero não foi determinante na escolha do eleitor, pois no primeiro turno o percentual de votos dados às candidaturas femininas chegou perto dos $60 \%$, 
o que reforçaria a hipótese de não haver resistência dos eleitores à ocupação dos postos de poder por mulheres. Porém, a votação diminuiu no segundo turno, quando houve uma clara migração dos votos de Marina Silva para José Serra.

Tabela 4. Eleições 2010/RS: distribuição dos candidatos - cargo x gênero

\begin{tabular}{c|c|c|c|c|c|c}
\hline \multirow{2}{*}{ cargo } & \multicolumn{2}{|c|}{ totais } & \multicolumn{2}{c|}{ homens } & \multicolumn{2}{c}{ mulheres } \\
\cline { 2 - 7 } & $\mathrm{n}$ & $\%$ & $\mathrm{n}$ & $\%$ & $\mathrm{n}$ & $\%$ \\
\hline governadores & 10 & $100 \%$ & 9 & $90 \%$ & 1 & $10 \%$ \\
\hline senadores & 10 & $100 \%$ & 7 & $70 \%$ & 3 & $30 \%$ \\
\hline deputado federal & 272 & $100 \%$ & 209 & $76,8 \%$ & 63 & $23,2 \%$ \\
\hline deputado estadual & 544 & $100 \%$ & 411 & $75,6 \%$ & 133 & $24,4 \%$ \\
\hline
\end{tabular}

Fonte: TSE.

Os dados referentes ao Rio Grande do Sul obedecem ao padrão nacional quanto às eleições proporcionais, todavia apresentam alguma diferenciação em relação às candidatas às eleições majoritárias. Apenas uma mulher se candidatou ao governo do estado; tratava-se da candidatura a reeleição da então governadora Yeda Crusius. Vale notar que a governadora teve muitos problemas durante seu mandato, destacando-se o difícil relacionamento com o vice-governador, a fragilidade de seu partido - PSDB - no estado e denúncias de malversação de recursos públicos envolvendo seu nome e de auxiliares próximos. Pouco antes das eleições, seu governo era muito mal avaliado nas pesquisas de opinião divulgadas na mídia regional ${ }^{10}$. Esse conjunto de fatores contribuiu para a derrota de Yeda, que ficou em terceiro lugar na disputa eleitoral.

Em relação às candidatas ao Senado o quadro é distinto. A candidata vitoriosa, Ana Amélia Lemos, apresenta um estilo político muito recorrente na política brasileira: não pertencendo ao campo político, transfere para este o capital acumulado em outra área de atividade. Jornalista da RBS, rede afiliada à Globo e maior empresa de comunicação do Sul do

${ }^{10}$ De acordo com pesquisa de opinião realizada pelo Ibope e publicada no jornal Zero Hora, em 9 de agosto de 2010, o governo Yeda era avaliado como ruim/péssimo por 37\% dos entrevistados, como regular por 31\%, e outros 30\% dos pesquisados achavam ótimo/bom. Essa tendência de reprovação ao seu governo foi uma constante nas sondagens de opinião realizadas no ano de 2010. 
país, Ana Amélia teve por longos anos uma coluna diária no jornal Zero Hora, além de participar dos programas de rádio e TV do grupo. Apesar de residir em Brasília há mais de 25 anos era presença constante no Estado, principalmente em eventos organizados pelo agronegócio. Um ano antes das eleições filiou-se ao PP, partido que mantém significativa força política entre os setores agrários, tendo sido eleita para um das vagas em disputa para o Senado. Foi a segunda mais votada, $\operatorname{com} 29,5 \%$ dos votos ${ }^{11}$. As outras duas candidatas pertenciam a partidos com pouca expressividade em termos de votação: Vera Guasso, candidata pelo PSTU, e Abigail Pereira, candidata pelo PCdoB. Ambas, diferentemente da vitoriosa Ana Amélia, possuíam longa militância partidária.

Em relação às candidaturas aos cargos de deputado federal e estadual, o primeiro ponto a ressaltar é que, apesar do crescimento numérico em relação às eleições de 2006, permanece o não cumprimento da lei de cotas, pois o percentual de mulheres candidatas não alcança o índice mínimo de $30 \%$ por gênero ${ }^{12}$. A mudança da legislação em 2010 não pareceu surtir o efeito desejado, já que não ocorreu a punição dos partidos que não cumpriram a lei ${ }^{13}$. Os resultados expostos na tabela abaixo permitem outras considerações.

Tabela 5. Resultado das eleições legislativas 2010/RS: vagas x candidatas $x$ eleitas

\begin{tabular}{c|c|c|c|c}
\hline \multirow{2}{*}{} & vagas & candidatas & \multicolumn{2}{|c}{ mulheres eleitas } \\
\cline { 2 - 5 } & $\mathrm{n}$ & $\mathrm{n}$ & $\mathrm{n}$ & $\%$ \\
\hline Senado & 2 & 3 & 1 & $50 \%$ \\
\hline Câmara dos Deputados & 31 & 63 & 2 & $6,5 \%$ \\
\hline Assembleia Legislativa & 55 & 133 & 8 & $14,5 \%$ \\
\hline
\end{tabular}

Fontes: CLIC RBS (2010a) e TRE/RS.

11 O primeiro colocado foi Paulo Paim, do PT, que concorria a reeleição, com 33,8\%. A vitória de Ana Amélia deixou de fora do Senado o ex-governador Germano Rigotto, do PMDB, que obteve $21,2 \%$ dos votos.

12 É importante destacar o crescimento no número de candidaturas femininas no RS. O índice de candidatas mulheres ao cargo de deputada federal foi de 11,83\% nas eleições de 2006, passando a 23,16\% em 2010. No caso da Assembleia Legislativa não é diferente: foram 13,8\% no pleito de 2006 e em 2010 esse índice aumentou para 24,4\% de mulheres candidatas. Fonte: TRE/RS.

3 Aliás, a ausência de punição pelo descumprimento da lei de cotas tem sido um dos temas presentes na literatura que debate a ausência de efetividade da lei (Araújo, 2005, 2009). 
A Tabela 5 demonstra que o crescimento quantitativo de candidaturas femininas não tem correspondência com os resultados, pois aponta o limitado desempenho das mulheres na disputa à Assembleia Legislativa e à Câmara dos Deputados. Se há um crescimento na bancada feminina na Assembleia Legislativa, o mesmo não acontece com a representação gaúcha das mulheres na Câmara dos Deputados.

Sobre as eleitas, é mister chamar a atenção para o fato de que nas duas Casas legislativas foram mulheres as candidatas mais votadas, sendo que, para a Câmara dos Deputados, Manuela d’Ávila, que concorria à reeleição pelo PCdoB, obteve uma das maiores votações do país em termos proporcionais. A candidata mais votada para a Assembleia Legislativa, Silvana Covatti, é do PP; também concorria à reeleição, mas, diferentemente de Manuela, sua carreira sempre esteve associada ao seu marido, reeleito deputado federal pelo mesmo partido ${ }^{14}$. Também chama a atenção que em ambas as Casas legislativas foi grande a ocorrência de reeleição das mulheres: no Legislativo estadual seis candidatas foram reconduzidas, das oito mulheres eleitas, e na Câmara dos Deputados as duas eleitas, Manuela d’Ávila e Maria do Rosário, já eram detentoras de mandatos.

Em síntese, a renovação das mulheres é bastante baixa se a compararmos com os dados gerais de renovação para o Rio Grande do Sul, que atinge o índice de $40 \%$ para a Assembleia Legislativa e 35,5\% para a Câmara dos Deputados. Isso pode indicar duas realidades bastante diversas: poucas lideranças emergentes capazes de angariar votos ou deputadas atuantes que justificariam a alta taxa de reeleição.

Além dos candidatos eleitos, os partidos necessitam de candidatos que, mesmo com poucas chances de sucesso, tenham densidade eleitoral capaz de somar votos. São eles, geralmente, candidatos mais regionalizados ou representantes de setores específicos, como sindicatos e movimentos sociais, que ajudam a legenda partidária a atingir o coeficiente eleitoral. Os dados abaixo permitem visualizar a posição de homens e mulheres quanto à votação geral, independente de terem ou não sido eleitos.

${ }_{14}$ Em 2010,Vilson Covatti estava buscando seu segundo mandato como deputado federal; antes de chegar à Câmara Federal, exerceu diversos mandatos como deputado estadual na Assembleia gaúcha. Nas eleições de 2006, quando concorreu pela primeira vez à Câmara, lançou sua esposa para deputada estadual e desde então o casal concorre em "dobradinha". Em ambas as eleições o casal Covatti foi bem sucedido. 
Tabela 6. Eleições 2010/RS: votação x gênero - Assembleia Legislativa

\begin{tabular}{c|c|c|c|c}
\hline \multirow{2}{*}{ faixa de votação } & \multicolumn{2}{|c|}{ mulheres } & \multicolumn{2}{c}{ homens } \\
\cline { 2 - 5 } & $\mathrm{n}$ & $\%$ & $\mathrm{n}$ & $\%$ \\
\hline 20.000 a 99.999 votos & 15 & $11,3 \%$ & 83 & $20,3 \%$ \\
\hline 10.000 a 19.999 votos & 08 & $6,0 \%$ & 51 & $12,5 \%$ \\
\hline 5.000 a 9.999 votos & 15 & $11,3 \%$ & 62 & $15,1 \%$ \\
\hline 1.000 a 4.999 votos & 23 & $17,3 \%$ & 109 & $26,7 \%$ \\
\hline até 999 votos & 72 & $54,1 \%$ & 104 & $25,4 \%$ \\
\hline total & 133 & $100 \%$ & 409 & $100 \%$ \\
\hline
\end{tabular}

Fonte: TSE.

Examinando-se as duas pontas dessa tabela, os mais e os menos votados, verifica-se uma inversão de posições: os homens (20,3\%) são percentualmente quase o dobro das mulheres como os mais votados e quase a metade como os menos votados $(25,4 \%)$, indicando que há muito mais candidatos homens efetivamente disputando vagas à Assembleia Legislativa do que candidatas mulheres. No caso das candidaturas para deputados federais, em que as mulheres tiveram desempenho muito fraco, a diferença entre homens e mulheres é ainda mais acentuada.

Tabela 7. Eleições 2010/RS: votação x gênero - Câmara dos Deputados

\begin{tabular}{c|c|c|c|c}
\hline \multirow{2}{*}{ faixa de votação } & \multicolumn{2}{|c|}{ mulheres } & \multicolumn{2}{c}{ homens } \\
\cline { 2 - 5 } & $\mathrm{n}$ & $\%$ & $\mathrm{n}$ & $\%$ \\
\hline + de 100.000 votos & 3 & $4,8 \%$ & 16 & $7,6 \%$ \\
\hline 20.000 a 99.999 votos & 2 & $3,2 \%$ & 37 & $17,5 \%$ \\
\hline 10.000 a 19.999 votos & 1 & $1,6 \%$ & 12 & $5,7 \%$ \\
\hline 5.000 a 9.999 votos & 1 & $1,6 \%$ & 19 & $9 \%$ \\
\hline 1.000 a 4.999 votos & 13 & $20,6 \%$ & 53 & $25,1 \%$ \\
\hline até 999 votos & 43 & $68,2 \%$ & 74 & $35,1 \%$ \\
\hline total & 63 & $100 \%$ & 211 & $100 \%$ \\
\hline
\end{tabular}

Fonte: TSE.

* Apesar das diferenças em termos de votação para a deputação federal e estadual, buscamos tornar as tabelas semeIhantes. A única variação está na inclusão da variável votação superior a 100 mil que consta da tabela que apresenta os dados da eleição para a Câmara de Deputados, buscando ressaltar as mulheres que tiveram expressiva votação. 
O quadro geral da posição das candidaturas das mulheres no Rio Grande do Sul vem ao encontro das posições comentadas na introdução do artigo. $\mathrm{O}$ número de candidatas aumentou sem que houvesse um aumento no número de eleitas. Porém, três aspectos chamam atenção: (a) entre as mulheres que foram eleitas há campeãs de votos; (b) elegeu-se uma senadora sem vida partidária; e (c) no primeiro turno das eleições presidenciais as candidatas mulheres tiveram a maioria dos votos. Tais dados permitem afirmar que não há resistência por parte dos eleitores a votar em mulheres, confirmando a hipótese geral. Portanto, as resistências parecem estar em outras áreas. A literatura, como vimos, tem acentuado muito a estrutura político eleitoral do país como um obstáculo a ser enfrentado pelas candidaturas femininas (Araújo, 2001, 2005, 2009).

No segmento deste artigo examinaremos um conjunto de candidatas que possuem importante cacife eleitoral para os partidos em função da densidade de votos conquistados no pleito de 2010. Apesar disso, nem todas as candidatas que fazem parte do estudo foram eleitas para a vaga que disputavam, fosse de deputada estadual ou deputada federal. Examinar quem são essas mulheres, ampliando o foco para além das eleitas, nos possibilitará avançar no entendimento da relação das mulheres com o sistema político-eleitoral.

\section{A disputa por vaga no Legislativo}

Nesta seção, a proposta é analisar a campanha das candidatas do estado do Rio Grande do Sul à Assembleia Legislativa e à Câmara dos Deputados nas eleições de 2010. Para cumprir o objetivo optamos por trabalhar com as candidatas que obtiveram acima de 10 mil votos, o que totaliza 23 candidatas à deputação estadual e seis à deputação federal. A opção pelo corte em $10 \mathrm{mil}$ votos é uma opção metodológica e se deve à ausência de mulheres nas altas faixas de votação, particularmente em relação ao número de candidatas ao Legislativo federal, como ficou demonstrado na Tabela 7. Para compreender quem são essas candidatas e o seu sucesso nas urnas partiremos dos dados constantes na ficha de inscrição junto ao TRE/RS, a prestação de contas e a propaganda eleitoral gratuita (HGPE) veiculada na televisão no horário eleitoral.

O sucesso ou insucesso em uma campanha eleitoral, tanto para homens como para mulheres, depende de muitas variáveis, mas duas delas assumem especial importância quando analisamos a disputa para o cargo de deputado estadual: visibilidade e investimento financeiro. A visibilidade está sendo medida pela frequência de exposição da candidata no horário eleitoral 
gratuito ao longo dos 45 dias de campanha oficial. Também se deve considerar, quanto à visibilidade, se a candidata já possui um mandato eletivo, o que lhe dá uma grande vantagem sobre as estreantes nas disputas eleitorais. As detentoras de mandato, independente do cargo, estão mais passíveis de estarem na mídia pela função que desempenham. Já a questão financeira é o aporte de dinheiro investido na campanha de cada postulante.

Financiamento de campanha é um ponto nevrálgico a todos os candidatos, especialmente no caso daqueles que disputam cargos para o Poder Legislativo. De acordo com a legislação eleitoral, os próprios candidatos são os responsáveis pela arrecadação de recursos para as campanhas, bem como pela prestação de contas desses gastos ao Judiciário. É razoável admitir que as candidatas detentoras de mandato sejam capazes de obter mais recursos que as adversárias sem mandato eletivo. Dessa forma, as duas variáveis anteriormente destacadas são cruciais e sinalizam as suas chances de vitória frente às demais. Em outras palavras, as deputadas estaduais que buscam a reeleição estão em grande vantagem perante as demais concorrentes, pois terão mais visibilidade (tanto na cobertura da mídia como no horário eleitoral gratuito) e, potencialmente, terão mais doações para suas campanhas. Isso porque mais facilmente acessam os financiadores e deles têm respostas positivas, já que são conhecidas pelo eleitorado, e com chance maior de sucesso, em detrimento das desconhecidas.

Na contabilização dos votos para a Assembleia Legislativa, chamaram a atenção alguns dados, além do crescimento da bancada feminina: as oito eleitas tiveram votações expressivas (todas acima de 38 mil votos), sendo que duas delas foram campeãs de voto: Silvana Covatti (PP) foi a deputada estadual mais votada entre os 55 eleitos; Juliana Brizola (PDT) teve o melhor desempenho entre seus colegas de partido. Enquanto a representante do PP era candidata à reeleição, Juliana pleiteava seu primeiro mandato no Parlamento estadual, visto que havia obtido uma excepcional votação em 2008 para vereadora de Porto Alegre. Além do excelente desempenho nas urnas, ambas tinham outro ponto em comum: entraram na política por herança familiar. Em 2006, Silvana elegeu-se deputada estadual pela primeira vez no rastro eleitoral do seu marido, Vilson Covatti, postulante à Câmara dos Deputados e com quem fez "dobradinha". Passados quatro anos, a "dobradinha eleitoral” se repetiu e ambos foram reeleitos. Já Juliana é neta do ex-governador Leonel Brizola e sempre usou o capital político do avô em suas 
campanhas. Identificamos, entre as 23 candidatas que alcançaram mais de 10 mil votos, cinco outras candidatas na situação de "herdeira". Entre as eleitas também destacamos Maria Helena Sartori (PMDB) ${ }^{15}$, e entre as não eleitas temos, por ordem de votação, Leila Fetter (PP), Elisabete Felice (PSDB), Helena Hermany (PP) e Mônica Leal (PP). Com exceção de Mônica, todas as demais ingressaram na disputa política pelas mãos de seus maridos. A diferença no caso de Mônica Leal é que ela é herdeira de seu pai, Coronel Pedro Américo Leal, conhecido político gaúcho com forte atuação durante o regime militar e por muitos anos vereador de Porto Alegre, a quem ela assessorou no Legislativo municipal por um longo período.

Tomando as declarações ao TRE/RS das 23 candidatas à deputada estadual sobre suas despesas de campanha temos que os seus gastos oscilaram muito. $\mathrm{O}$ volume de recursos recebido por essas candidatas variou de $\mathrm{R} \$ 10 \mathrm{mil}$ até $\mathrm{R} \$ 277$ mil reais. Pelos dados apresentados constatamos que a líder em arrecadação foi a campeã de votos Silvana Covatti. A seguir apresentamos as despesas das oito candidatas eleitas.

Tabela 8. Eleições 2010/RS: valor unitário do voto resultado da votação final x despesas de campanha - candidatas eleitas à Assembleia Legislativa com mais de 10 mil votos

\begin{tabular}{c|c|c|c}
\hline candidatas & total de votos & total de despesas (R\$) & valor por voto (R\$) \\
\hline 1. Silvana Covatti (PP) & 85.604 & $277.101,65$ & 3,23 \\
\hline 2. Juliana Brizola (PDT) & 61.305 & $94.765,36$ & 1,54 \\
\hline 3. Stela Farias (PT) & 48.070 & $99.987,55$ & 2,08 \\
\hline 4. Miriam Marroni (PT) & 45.450 & $10.256,00$ & 0,22 \\
\hline 5. Marisa Formolo (PT) & 43.860 & $43.691,41$ & 0,99 \\
\hline 6. Ma. Helena Sartori (PMDB) & 38.958 & $73.734,88$ & 1,89 \\
\hline 7. Ana Affonso (PT) & 38.525 & $110.132,67$ & 2,85 \\
\hline 8. Zila Breitenbech (PSDB) & 34.676 & $85.550,43$ & 2,46 \\
\hline
\end{tabular}

Fonte: Tabela elaborada pelas autoras a partir dos dados disponíveis no site do TRE/RS

Os dados acima nos revelam que a maioria das mulheres que se elegeram deputadas estaduais no RS também estão entre as 10 maiores arrecadadoras. Em ordem de arrecadação estão: Silvana Covatti, Ana Affonso, Stela Farias,

\footnotetext{
15 Miriam Marroni (PT) não foi incluída por ter carreira solo, embora tenha concorrido em "dobradinha"
} com o marido, Fernando Marroni, candidato do PT ao cargo de deputado federal. 
Juliana Brizola, Zilá Breitenbach e Maria Helena Sartori. Do ponto de vista partidário existe uma distribuição entre os principais partidos do estado; entretanto, merecem destaque o PP e o PT, que somam as maiores contribuições. A explicação pode estar no potencial de votos das candidatas apresentadas por essas legendas, assim como no fato de ambos serem partidos bem estruturados no Estado, o que ajudaria na campanha dessas postulantes. Também cabe destacar que, das seis eleitas que fazem parte do grupo com maior financiamento, quatro já eram detentoras de mandato e pleiteavam reeleição. Apenas Ana Affonso (PT) e Juliana Brizola (PDT) não ocupavam uma cadeira na Assembleia gaúcha, mas, mesmo assim, não eram estreantes na disputa eleitoral. Ambas eram vereadoras em suas respectivas cidades, São Leopoldo e Porto Alegre.

Vale comparar os dados acima com os daquelas que alcançaram votação acima de 10 mil votos.

Tabela 9. Eleições 2010/RS: valor unitário do voto resultado da votação final x despesas de campanha - candidatas não eleitas à Assembleia Legislativa com mais de 10 mil votos

\begin{tabular}{c|c|c|c}
\hline candidatas & total de votos & total de despesas (R\$) & valor por voto (R\$) \\
\hline 9. Leila Fetter (PP) & 35.634 & $130.160,91$ & 3,65 \\
\hline 10. Elisabete Felice (PSDB) & 33.131 & $39.118,42$ & 1,18 \\
\hline 11. Jussara Cony (P(doB) & 30.910 & $41.253,84$ & 1,33 \\
\hline 12. Neusa Kempfer (PMDB) & 25.171 & $30.332,16$ & 1,20 \\
\hline 13. Helena Hermany (PP) & 21.797 & $37.697,43$ & 1,72 \\
\hline 14. Maria Eunice Wolf (PT) & 20.871 & $49.080,30$ & 2,35 \\
\hline 15. Maria Celeste (PT) & 19.549 & $87.743,99$ & 4,48 \\
\hline 16. Maria Lorena (PDT) & 19.479 & $96.598,34$ & 4,95 \\
\hline 17. Mônica Leal (PP) & 19.259 & $104.742,95$ & 5,43 \\
\hline 18. Nadir Machado (PTB) & 14.937 & $52.307,49$ & 3,50 \\
\hline 19. Nilvia Pereira (PT) & 13.456 & $64.989,15$ & 4,82 \\
\hline 20. Elisabete Vargas (PMDB) & 13.136 & $22.416,80$ & 1,70 \\
\hline 21. Juçara Vieira (PT) & 12.597 & $57.238,10$ & 4,54 \\
\hline 22. Lorena Arrue Dias (PSDB) & 12.171 & $10.779,35$ & 0,88 \\
\hline 23. Carina Silveira (PMDB) & 12.084 & $13.879,53$ & 1,14 \\
\hline
\end{tabular}

Fonte: Tabela elaborada pelas autoras a partir dos dados disponíveis no site do TRE/RS.

A maioria das mulheres do grupo das não eleitas não era novata no jogo político-eleitoral: algumas eram/foram vereadoras, outras eram/foram se- 
cretárias municipais ou de Estado, e outras ainda prefeitas e vice-prefeitas ${ }^{16}$. A exceção nesse grupo foi Leila Fetter (PP): no pleito de 2006 ela ficou como suplente, mas em dezembro de 2009 assumiu, em definitivo, a titularidade como deputada estadual. Mesmo pleiteando a reeleição, não obteve sucesso, apesar de ter conquistado mais de 35 mil votos, já ter exercido representação e ter tido verba elevada para gastar na campanha. Leila, na verdade, foi mais votada do que a última eleita (Zilá Breitenbach/PSDB), não conquistando a vaga devido à votação obtida pelo $\mathrm{PP}$, o que impactou as vagas conquistadas pelo partido. A eleição de um(a) candidato(a) com menor votação do que outro(a) faz parte da lógica do atual sistema eleitoral brasileiro. No sistema de votação proporcional de lista aberta é o partido/coligação que conquista(m) as vagas, e estas são distribuídas internamente à lista partidária, conforme o desempenho nas urnas de cada candidato. Apesar de ter sido a oitava mulher mais votada, ela ficou de fora da Assembleia Legislativa.

Dando continuidade à análise dos gastos de campanha das 23 candidatas mais votadas à Assembleia Legislativa, é interessante abordar o valor unitário do voto dessas mulheres. Cabe perguntar: o voto das oito candidatas eleitas foi mais caro ou mais barato que o voto das não eleitas? A partir dos dados disponíveis constatamos que os valores são díspares e podemos identificar três grupos: no primeiro bloco estão aquelas que gastaram até $\mathrm{R} \$ 1,50$ por voto; no outro, estão as candidatas que gastaram entre R \$ 1,50 e R \$ 3,00; e, por fim, o grupo que teve gasto unitário superior a $\mathrm{R} \$ 3,00^{17}$.

Os valores dos votos apresentados nas tabelas 8 e 9 suscitam reflexões em torno do valor unitário do voto. A maioria das eleitas à deputação estadual teve um gasto por voto na faixa entre $\mathrm{R} \$ 1,50$ e $\mathrm{R} \$ 3,00$; apenas duas deputadas estão na faixa 1 , onde o voto saiu por menos de $\mathrm{R} \$ 1,50$, e uma das eleitas gastou mais de $\mathrm{R} \$ 3,00$ por voto. Isso nos sinaliza que o voto das eleitas, em sua maioria, teve baixo custo, já que para sete deputadas estaduais o voto custou menos de $\mathrm{R} \$ 3,00$. Comparando-se esses valores com a proposta existente na Câmara dos Deputados, que prevê a destinação ao TSE de R\$

\footnotetext{
${ }^{6}$ Dessas 23 candidatas apenas Elisabete Felice (PSDB) e Maria Eunice Dias (PT) nunca exerceram mandato eletivo.

7 Na faixa 1 (até R\$1,50) estão sete candidatas: Miriam Marroni, Lorena Dias, Marisa Formolo, Carine Silveira, Elisabete Felice, Neusa Kempfer e Jussara Cony. Na faixa $2(\mathrm{R} \$ 1,50$ até $\mathrm{R} \$ 3,00)$ encontram-se oito postulantes: Juliana Brizola, Elisabete Vargas, Helena Hermany, Ma. Helena Sartori, Stela Farias, Ma. Eunice Wolf, Zila Breitenbach e Ana Affonso. Na terceira faixa (acima de R\$3,00) também temos oito candidatas: Silvana Covatti, Nadir Machado, Leila Fetter, Maria. Lorena, Maria. Celeste, Juçara Vieira, Nilvia Pereira e Mônica Leal.
} 
7,00 por eleitor para calcular a verba a ser destinada aos partidos em ano eleitoral, caso o financiamento público de campanha venha a ser adotado no Brasil $^{18}$, as deputadas gaúchas tiveram uma votação de baixo custo.

A maioria das mulheres que teve maior gasto por voto e que se encontra na faixa 3 não se elegeu. Todas as oito candidatas dessa faixa de gasto também estavam entre os maiores financiamentos de campanha, acima de $\mathrm{R} \$ 50$ mil reais; entretanto, isso não se converteu em voto, pois apenas uma conquistou vaga na Assembleia Legislativa. Tais dados permitem que se relativize a importância do volume de recursos no processo eleitoral como determinante de vitórias. As mulheres que são detentoras de mandato e estão em busca da sua reeleição tendem a gastar menos por voto do que aquelas que não são detentoras. Estas precisam compensar sua desvantagem gastando mais em suas campanhas.

Analisando mais detidamente as oito mulheres que se elegeram deputadas estaduais, constatamos que cinco buscavam reeleição e três eram vereadoras em grandes municípios do $\mathrm{RS}^{19}$. Todas elas possuem fortes vínculos partidários e sempre estiveram filiadas a um mesmo partido: quatro no PT, uma no PDT, uma no PP, uma no PMDB e uma no PSDB. Das eleitas, seis delas estavam entre as 10 maiores arrecadadoras e, associando a isso seu capital político, elas conseguiram potencializar suas chances de vitória.

O Horário Gratuito de Propaganda Eleitoral (HGPE) veiculado pela televisão é, para muitos candidatos ou candidatas, um dos únicos espaços de visibilidade na mídia. A propaganda eleitoral para o cargo de deputado federal foi veiculada às segundas, quartas e sextas-feiras ${ }^{20}$, e às terças, quintas e sábados ocorria a propaganda das candidaturas à deputado estadual ${ }^{21}$. O período da propaganda eleitoral gratuita totalizou sete dias no mês de agosto e 13 dias no mês de setembro. Assim, as candidaturas poderiam chegar a um total máximo de 20 inserções. Como nossa análise recai sobre o grupo das mulheres, não estabeleceremos comparações entre os dois gêneros, mas somente intragênero feminino.

18 O valor de R\$7,00 consta no PLS 268/2011, projeto que trata do financiamento público de campanha, e que atualmente aguarda para ser colocado em votação no plenário da Câmara dos Deputados, cujo relator é o deputado Henrique Fontana (PT/RS).

19 As vereadoras que concorreram à deputação estadual e se elegeram foram: Juliana Brizola, vereadora em Porto Alegre; Miriam Marroni, representante na Câmara Municipal de Pelotas; e Ana Affonso, vereadora em São Leopoldo.

20 A propaganda eleitoral dos deputados federais ocorreu nos seguintes dias: 18, 20, 22, 25, 27 e 30 de agosto, e 01, 03, 06, 08, 10, 13, 15, 17, 20, 22, 24, 27 e 29 de setembro.

21 A propaganda gratuita dos candidatos a deputado estadual foi veiculada nos seguintes dias: 17, 19, 21, 24, 26, 28 e 31 de agosto; e 2, 4, 7, 9, 11, 14, 16, 18, 21, 23, 25, 28 e 30 de setembro. 
A análise do HGPE mostra que, das 63 candidatas aptas a concorrer ao cargo de deputada federal conforme o Tribunal Superior Eleitoral, apenas 38 tiveram suas imagens e/ou falas veiculadas ${ }^{22}$. Já entre as mulheres que disputavam uma vaga na Assembleia Legislativa do RS, 92 tiveram acesso ao horário eleitoral e 41 nunca apareceram no espaço televisivo destinado à campanha partidária ${ }^{23}$.

Retomando as candidaturas das 23 mulheres que conquistaram mais de 10 mil votos, temos que todas elas estiveram presentes no horário da propaganda gratuita. A forma desta inserção variou de acordo com as estratégias dos partidos: o Partido Progressista veiculou apenas a foto do/a concorrente e ao fundo um locutor apresentava o nome e o número do candidato/a. As quatro candidatas mais votadas do PP tiveram um tratamento muito equânime: Silvana Covatti, Leila Fetter e Mônica Leal apareceram sete vezes no decorrer do HGPE; a exceção foi Helena Hermany, que teve 12 inserções. Como a campanha oficial desenrola-se ao longo de seis semanas, percebemos que essas mulheres apareceram apenas uma vez na semana no HGPE, exceto Helena Hermany, que apareceu duas vezes.

A única candidata que apareceu todos os dias no programa eleitoral foi Jussara Cony, do PCdoB. Essa candidata teve 20 inserções no HGPE e sempre usou esse espaço para dirigir-se ao eleitorado. Vale notar que no pequeno PCdoB Cony é uma destacada liderança e grande campeã de votos. Seu capital eleitoral é muito superior ao do partido. Apesar da frequência das inserções, suas falas totalizaram menos de 3 minutos ao longo dos 45 dias de propaganda oficial. Como o PCdoB estava coligado para as proporcionais ao PSB e ao $\mathrm{PR}$, formando a coligação Unidade pelo Rio Grande, seu tempo total diário no horário eleitoral gratuito chegava a $2 \mathrm{~m} 5 \mathrm{~s} .{ }^{24}$. Os comunistas, dispondo de pouco tempo no HGPE, investiram nas suas principais lideranças, Jussara Cony e Raul Carrion ${ }^{25}$. Entretanto, apesar do tempo privilegiado destinado

${ }^{22}$ De fato, 39 candidatas aparecem no HGPE: uma candidata do PSDB renunciou após quatro aparições no programa.

23 Ao todo foram inscritas junto ao TRE/RS 169 candidatas à Assembleia Legislativa, entretanto no decorrer da campanha 21 tiveram suas candidaturas indeferidas e 15 renunciaram.

24 Dentro da coligação o PSB dispunha diariamente de 52 segundos, o PR de 48 segundos e o PCdoB de apenas 25 segundos, totalizando ao longo dos 45 dias de campanha oficial menos de 42 minutos.

25 Tanto Jussara Cony como Raul Carrion possuem uma longa trajetória política dentro do PCdoB. Cony já fora vereadora na capital e deputada estadual e em 2010 estava ocupando um importante cargo diretivo em um órgão federal. Já Carrion estava no exercício de seu mandato como vereador de Porto Alegre quando se lançou na disputa por uma vaga no Legislativo estadual. 
a Cony, ela não logrou sucesso, já que a vaga conquistada pelo PCdoB foi ocupada por Raul Carrion.

As quatro candidatas do PMDB - Maria Helena Sartori, Neusa Kempfer, Elisabete Vargas e Carine Frassoni - apareceram apenas duas ou três vezes no HGPE durante toda a campanha eleitoral. Essas mulheres falavam em média 20 segundos a cada aparição. Dessas, apenas Maria Helena Sartori logrou sucesso e obteve sua reeleição. Também o PSDB deu pouco espaço às candidaturas femininas: tanto Zilá Breitenbach, que buscava reeleição, como Elisabete Felice e Lorena Arrue apareceram apenas uma vez durante todo o HGPE. A fala de cada uma das candidatas durou apenas 30 segundos ao longo das seis semanas de propaganda oficial.

As candidatas do PDT, Juliana Brizola e Lorena Mayer, e do PTB, Nadir Machado, tiveram duas ou três inserções na propaganda partidária e suas falas duravam, em média, 15 segundos a cada aparição. Já o PT veiculou de forma igualitária a propaganda das suas oito candidatas, independentemente de serem detentoras de mandato ou não. Todas elas tiveram cinco inserções no decorrer da campanha eleitoral e suas falas e/ou exposição de foto somavam no máximo um minuto. Dessas oito candidatas, quatro conquistaram uma vaga na Assembleia Estadual, sendo que delas três foram reeleitas e apenas uma - Ana Affonso - estreou como deputada estadual.

Tabela 10: Votação final x inserções no Programa Eleitoral Gratuito x gastos de campanha das candidatas à Assembleia Legislativa/RS: candidatas eleitas

\begin{tabular}{c|c|c|c}
\hline candidatas & total de votos & $\begin{array}{c}\mathrm{n}^{0} \text { de inserções e } \\
\text { tempo no HGPE }\end{array}$ & $\begin{array}{c}\text { total de despesas } \\
\text { (R\$) }\end{array}$ \\
\hline Silvana Covatti (PP) & 85.604 & $7(1 \mathrm{~m})$ & $277.101,65$ \\
\hline Juliana Brizola (PDT) & 61.305 & $3(53 \mathrm{~s})$ & $94.765,36$ \\
\hline Stela Farias (PT) & 48.070 & $5(50 \mathrm{~s})$ & $99.987,55$ \\
\hline Miriam Marroni (PT) & 45.450 & $5(1 \mathrm{~m})$ & $10.256,00$ \\
\hline Marisa Formolo (PT) & 43.860 & $5(55 \mathrm{~s})$ & $43.691,41$ \\
\hline Maria Helena Sartori (PMDB) & 38.958 & $3(1 \mathrm{~m})$ & $73.734,88$ \\
\hline Ana Affonso (PT) & 38.525 & $5(55 \mathrm{~s})$ & $110.132,67$ \\
\hline Zila Breitenbach (PSDB) & 34.676 & $1(30 \mathrm{~s})$ & $85.550,43$ \\
\hline
\end{tabular}

Fonte: TSE e Horário Gratuito de Propaganda Eleitoral (HGPE). 
Como fica claro na Tabela 10, os partidos deram pouco espaço às candidaturas femininas no HGPE. E mesmo aquelas mulheres que já eram deputadas não tiveram um tratamento privilegiado. Retomando as duas dimensões visibilidade e financiamento de campanha - podemos constatar que o tempo de exposição durante o Horário Eleitoral Gratuito não é determinante para o sucesso ou insucesso de uma candidatura. Tivemos duas mulheres com recorde de inserções - Jussara Cony e Helena Hermany - que não foram eleitas deputadas estaduais. Também tivemos duas candidatas com um elevado orçamento de campanha, mais de $\mathrm{R} \$ 100$ mil reais, que não conquistaram uma vaga na Assembleia Legislativa, Leila Fetter e Mônica Leal, ambas do PP. Ainda sobre a variável visibilidade, talvez o que faça a diferença no resultado final seja o capital político dessas mulheres e a sua condição de já possuírem um mandato de deputada estadual. Esse trabalho ao longo de quatro anos, e sua visibilidade, é que faz a maior diferença.

Os dados das candidatas ao cargo de deputada federal apontam para resultados semelhantes. São seis candidatas que alcançaram mais de 10 mil votos, três com votação acima de 100 mil; porém só duas delas, Manuela d’Ávila (PCdoB) e Maria do Rosário (PT), foram eleitas. Luciana Genro (PSOL) recebeu votos suficientes para sua reeleição, mas ficou de fora da Câmara dos Deputados em função do baixo desempenho do seu partido ${ }^{26}$. As demais candidatas são: Emília Fernandes (PT), Dra. Suzana (PT) e Jane Andreola (PP).

Diferentemente do que aconteceu com muitas candidatas à Assembleia Legislativa, as trajetórias das candidatas à deputação federal, que alcançaram mais de 10 mil votos, não estão baseadas em herança familiar. Seu capital político parece estar vinculado à atuação em movimentos sociais, movimento estudantil e ao desempenho parlamentar.

As quatro candidatas mais votadas possuem significativo capital político: Manuela d’Ávila, Maria do Rosário, Luciana Genro e Emília Fernandes possuem longa carreira política e disputavam a reeleição. As três primeiras colocadas também haviam sido candidatas à Prefeita de Porto Alegre nas eleições municipais de $2008^{27}$.

\footnotetext{
26 No pleito de 2010 para eleger cada deputado federal, o partido ou coligação necessitaria atingir 261.686 votos. O PSOL, que saiu sozinho na eleição, teve menos de 170 mil votos no Rio Grande do Sul.

27 No total foram oito candidatos à Prefeitura de Porto Alegre nas eleições de 2008. Quatro candidatas eram mulheres: Maria do Rosário (PT), Manuela d'Ávila (PCdoB), Luciana Genro (Psol) e Vera Guasso (PSTU). Os demais candidatos foram José Fogaça (PMDB), Onyx Lorenzoni (DEM), Nelson Marchezan Jr. (PSDB) e Carlos Gomes (PHS).
} 
Manuela já se transformou em um fenômeno eleitoral, com 482.590 votos, foi a candidata mais votada entre todos os candidatos ao cargo de deputado federal no Rio Grande do Sul. Ela iniciou sua militância no movimento estudantil universitário, que marcou sua carreira política, focada especialmente nos jovens. Em 2004 foi eleita vereadora da capital pelo PCdoB, em 2006 foi eleita deputada federal com expressiva votação, o que possibilitou sua candidatura à Prefeitura de Porto Alegre dois anos depois desse pleito. A campanha de Manuela d'Ávila ao Executivo Municipal alcançou tal sucesso que em determinado momento chegou a ameaçar a vaga da candidata do PT ao segundo turno do pleito ${ }^{28}$.

Maria do Rosário, a segunda mais votada, com 143.128 votos, iniciou sua carreira também no PCdoB, conquistando seu primeiro mandato como vereadora de Porto Alegre. Em 1994, durante o seu primeiro mandato transferiu-se para o PT, onde permanece até hoje. No PT foi reeleita vereadora, tendo sido campeã de votos, com mais de 20 mil; seu mandato foi interrompido para se eleger deputada estadual em 1998, quando foi a segunda mais votada, com mais de 77 mil votos. Em 2003, assumiu seu primeiro mandato como deputada federal e, em 2006, foi reeleita, ficando sempre entre os candidatos mais votados. No ano de 2008, concorreu à Prefeitura de Porto Alegre e disputou o segundo turno com o candidato vitorioso, José Fogaça (PMDB). Em 2010 foi reeleita deputada federal, alcançando a segunda maior votação entre as candidatas. Sua destacada atuação legislativa relacionada ao tema dos direitos humanos ensejou o convite da presidenta Dilma Rousseff para assumir a Secretaria de Direito Humanos da Presidência da República em 2011.

Manuela d’Ávila e Maria do Rosário possuem uma trajetória comum: iniciaram a carreira política no PCdoB, conquistaram por esse partido seu primeiro mandato como vereadoras em Porto Alegre; com votações crescentes chegaram rapidamente à Câmara dos Deputados. Devido ao desempenho eleitoral e parlamentar, concorreram nas eleições de 2008 à Prefeitura de Porto Alegre.

A carreira política de Luciana Genro, a exemplo do que ocorreu com Manuela e Maria do Rosário, teve início no movimento estudantil. Militante do PT, ela foi eleita deputada estadual em 1994, sendo reeleita em 1998 para

${ }^{28}$ Somente a totalização dos votos dissipou a incerteza de quem disputaria o segundo turno com José Fogaça, que obteve $39,9 \%$ da preferência eleitoral. A candidata petista obteve quase $21 \%$ dos votos contra 13,95\% de Manuela (Pinto e Moritz, 2009). 
mais um mandato; em 2002 elegeu-se deputada federal. Devido à sua crítica ao governo Lula foi expulsa do partido junto com a senadora Heloísa Helena e o deputado Babá, em dezembro de 2003. Com eles fundou o PSOL, partido pelo qual concorreu a deputada federal em 2006, tendo sido a deputada mais votada na cidade de Porto Alegre, com 185 mil votos. Em 2008 concorreu à Prefeitura da capital, alcançando significativa votação, fortalecendo a legenda do seu partido e consolidando ainda mais sua carreira política, como demonstram os 129.501 que recebeu nas eleições de 2010.

Como destacado, a trajetória das três deputadas federais candidatas à reeleição não está vinculada à herança familiar, mas à atuação no movimento estudantil e partidário. É preciso ressaltar o caso de Luciana Genro do PSOL. Luciana é filha de Tarso Genro (PT), eleito governador do estado do RS em 2010, de quem foi correligionária de partido até a expulsão em 2003, quando exercia o mandato de deputada federal. Porém, não é possível atribuir seu sucesso eleitoral à herança familiar.

Sem dúvida, a ampla visibilidade propiciada pela disputa ao cargo majoritário da capital trouxe reflexos para cada uma das três candidatas em termos de importância da candidatura no partido, repercutindo em maior espaço no Programa Eleitoral Gratuito, maior capacidade de arrecadação financeira e significativa votação final ${ }^{29}$.

Emília Fernandes, também candidata à reeleição, ficou como suplente nas eleições de 2006 e assumiu a titularidade do cargo em fevereiro de 2009. Emília possuía uma carreira política bastante tradicional até o momento em que se elegeu senadora. Pedagoga e militante do Sindicato dos Professores do Rio Grande do Sul (CPERGS), iniciou sua carreira política como vereadora em Santana do Livramento, em 1982, pelo PDT. Ocupou o cargo por três mandatos consecutivos. Em 1994, Emília foi a primeira mulher gaúcha a se eleger senadora pelo PTB e no transcurso do mandato migrou para o PT. Tendo sido eleita por força da grande popularidade no estado do comunicador Sergio Zambiasi, de quem foi afilhada política, não foi bem-sucedida na reeleição ao Senado em 2002 e na candidatura a deputada federal no pleito seguinte. No governo Lula, foi chamada a atuar como ministra da Secretaria Especial de Políticas para as Mulheres. Atualmente, Emília Fernandes, além de atuar no Fórum de Mulheres do Mercosul, também é secretária executiva

${ }^{29}$ A biografia das três candidatas está muito bem descrita no texto de PINTO e MORITZ (2009) que analisa as candidaturas femininas a Prefeitura de Porto Alegre nas eleições de 2008. 
do CODESUL (Conselho de Desenvolvimento e Integração Sul), junto ao Governo do Estado do RS ${ }^{30}$.

Cabe ainda comentar que nenhuma das seis candidatas que tiveram mais de 10.000 votos era novata: Dra. Suzana (PT) foi vereadora em Três Passos e exerce o mandato de vice-prefeita do município de Campo Bom, e Jane Andreola (PP) estava no segundo mandato como vereadora no município de Vacaria.

Em relação à variável financiamento de campanhas, alguns dados são reveladores. As seis candidatas com votação acima de 10 mil votos foram também aquelas com maior despesa de campanha, o que sugere a relação entre recursos financeiros e votos. Entretanto, essa relação não parece ser uma equação tão simples quando examinamos os dados. As duas candidatas eleitas foram aquelas que mais arrecadaram e consequentemente que mais gastaram. Porém, alta despesa de campanha não necessariamente resulta em alta votação. Veja-se o caso da Emília Fernandes, que teve gastos acima de 700 mil reais, mas uma votação abaixo de 50 mil votos, contrastando com Luciana Genro, que gastou três vezes menos e conseguiu mais que o dobro dos votos de Emília.

Tabela 11. Valor unitário do voto resultado da votação final $x$ despesas de campanha - candidatas à deputada federal/RS com mais de 10 mil votos

\begin{tabular}{c|c|c|c|c}
\hline candidatas & resultado eleitoral & total de votos & total de despesas (R\$) & valor por voto (R\$) \\
\hline Manuela d'Ávila (PCdoB) & eleita & 482.590 & $1.048 .275,55$ & 2,17 \\
\hline Maria do Rosário (PT) & eleita & 143.128 & $861.941,32$ & 6,02 \\
\hline Luciana Genro (PSOL) & não eleita & 129.501 & $230.354,01$ & 1,77 \\
\hline Emília Fernandes (PT) & não eleita & 49.413 & $752.888,10$ & 15,23 \\
\hline Dra. Suzana (PT) & não eleita & 20.025 & $57.418,25$ & 2,86 \\
\hline Jane Andreola (PP) & não eleita & 16.012 & $72.399,70$ & 4,52 \\
\hline
\end{tabular}

Fonte: TSE.

A partir dos dados acima, constata-se que o voto para deputada federal é mais caro do que o voto para deputada estadual, conforme tabelas 9 e 10 . As duas candidatas eleitas tiveram gastos por voto bastante distintos. Manuela

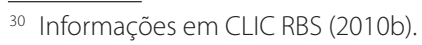


d’Ávila teve a campanha mais cara, porém sua significativa votação acabou por baixar o custo do voto individual $(\mathrm{R} \$ 2,17)$, ficando atrás apenas de Luciana Genro, que gastou menos de $\mathrm{R} \$ 2,00$ por voto. Maria do Rosário foi a segunda mais votada e a segunda em despesas de campanha; apesar de sua significativa votação, o valor unitário de seu voto não foi baixo (R\$ $6,02)$. Mas o dado mais curioso é o custo do voto individual da candidata não eleita Emília Fernandes, acima de R\$ 15,00.

As quatro candidatas à reeleição ao cargo de deputado federal, ora em análise, são as maiores arrecadadoras de recursos financeiros e aquelas que conseguiram a maior votação. Porém, diferem em relação ao custo do voto individual, que oscila entre $\mathrm{R} \$ 1,77$ até $\mathrm{R} \$ 15,23$. Assim, os recursos financeiros são importantes para uma campanha bem-sucedida, mas não são suficientes para a eleição; o capital político e a visibilidade que ele produz parecem potencializar suas chances de vitória: a terceira candidata mais votada, Luciana Genro, que obteve mais de 100 mil votos, tem despesas significativas de campanha, mas muito aquém das duas candidatas eleitas e mesmo de Emília Fernandes, a quarta mais votada, que embora tenha gasto três vezes mais do que Luciana, acabou tendo quase 70 mil votos a menos.

Como destacado anteriormente, apenas 38 candidatas a deputada federal tiveram acesso ao HGPE, algumas delas apenas veicularam foto, o que demonstra uma restrita presença das mulheres na propaganda eleitoral.

Considerando a possibilidade de até 20 inserções das candidatas ao cargo de deputada federal, mais da metade das candidatas (60\%) que aparecem no HGPE teve a imagem e/ou fala veiculada na televisão no máximo cinco vezes, dado que reforça a pouca visibilidade dada pelos partidos às candidatas. $\mathrm{O}$ percentual de candidatas que apresentaram sua plataforma eleitoral no máximo em 10 inserções foi de 74,29\%, aparecendo apenas na metade do tempo disponível de propaganda para o cargo a que concorreram. Já as mulheres com presença mais frequente, entre 16 e 20 inserções, foram em número bem menor: apenas sete candidatas $(20 \%)^{31}$. A questão agora é perceber se há relação entre presença no programa e altos índices de votação.

31 Inserções das candidatas à Câmara dos Deputados/RS no HGPE: do total de 38 candidatas presentes no HGPE, 21 candidatas (60\%) aparecem até 5 vezes; 05 candidatas (14,3\%) aparecem até 10 vezes; 02 candidatas (5,7\%), aparecem até 15 vezes e 07 candidatas (20\%) aparecem até 20 vezes. 
Tabela 12. Votação final x inserções no Programa Eleitoral Gratuito x gastos de campanha das candidatas à Câmara dos Deputados/RS com mais de 10.000 votos

\begin{tabular}{c|c|c|c}
\hline candidatas & total de votos & n. de inserções e tempo no HGPE & total de despesas (R\$) \\
\hline Manuela d'Ávila (PCdoB) & $482.590(\mathrm{E})$ & $19(6 \mathrm{~m} 25 \mathrm{~s})$ & $1.048 .275,55$ \\
\hline Maria do Rosário (PT) & $143.128(\mathrm{E})$ & $20(2 \mathrm{~m} 37 \mathrm{~s})$ & $861.941,32$ \\
\hline Luciana Genro (Psol) & 129.501 & $17(7 \mathrm{~m} 20 \mathrm{~s})$ & $230.354,01$ \\
\hline Emília Fernandes (PT) & 49.413 & $18(1 \mathrm{~m} 59 \mathrm{~s})$ & $752.888,10$ \\
\hline Dra. Suzana (PT) & 20.025 & $20(2 \mathrm{~m} 10 \mathrm{~s})$ & $57.418,25$ \\
\hline Jane Andreola (PP) & 16.012 & $05(2 \mathrm{~m} 49 \mathrm{~s})$ & $72.399,70$ \\
\hline
\end{tabular}

Fonte: TSE e Horário Gratuito de Propaganda Eleitoral (HGPE).

Das sete candidatas que mais aparecem no HGPE (tendo entre 16 e 20 inserções), quatro constam na lista das mais votadas, como pode ser visto na Tabela $12^{32}$, sendo duas delas as candidatas eleitas ao cargo de deputada federal. Diferente do que ocorreu em relação ao Legislativo estadual, o PT não disponibilizou o mesmo tempo de propaganda para suas candidatas: Maria do Rosário, com 20 inserções e tempo de 2m37s, é seguida de Dra. Suzana, também com 20 inserções, porém com tempo de $2 \mathrm{~m} 10$ s, e, por fim, aparece Emília Fernandes com 17 inserções e tempo de $1 \mathrm{~m} 59$ s. A soma dos três tempos das candidatas do PT é quase igual ao tempo de Manuela (6m25s em 19 inserções) e inferior ao tempo de Luciana Genro (7m20s em 17 inserções), o que permite perceber a importância dessas duas candidaturas para os respectivos partidos. A candidata Jane Andreola, do PP, apresentou um número bem menor de inserções (5), mas ao todo o seu tempo atingiu $2 \mathrm{~m} 49$ s, o que é maior do que o tempo individual de outras candidatas, como, por exemplo, as postulantes do PT.

Os dados não permitem afirmar que a maior presença no HGPE equivale a uma maior votação. Como já apontado em relação às candidatas ao cargo de deputadas estaduais, a visibilidade no HGPE e o apoio financeiro são insuficientes para sozinhos explicar uma campanha vitoriosa, pois devemos incorporar outras dimensões explicativas para compreender o sucesso ou

32 As duas candidatas com número significativo de inserções no HGPE, mas com baixa votação são: Jéssica Campos Nucci do PSTU -19 inserções (3m49s), votação de 2.014 e gastos de campanha R\$ 2.534,00; Renata Garcia Teixeira do PR - 19 inserções (1 m15s), votação de 881 e despesas de campanha de $R \$ 6.063,49$. 
insucesso nas urnas. No caso das três candidatas que alcançaram acima de 100 mil votos, é possível supor que o capital político acumulado em mandatos anteriores, particularmente como deputadas federais, somado à presença em campanhas bem construídas na disputa eleitoral à Prefeitura de Porto Alegre, possibilitou maior visibilidade e facilidade na arrecadação de recursos financeiros, tornando-se fatores significativos para o sucesso na votação.

\section{Conclusão}

O resultado das eleições gerais de 2010 no Rio Grande do Sul mostrou que as mulheres continuam com as mesmas dificuldades de se elegeram para os cargos legislativos, apesar da nova lei de cotas. Um primeiro ponto a ser observado é que essa lei não foi cumprida pela grande maioria dos partidos, entretanto, não é o seu descumprimento o grande responsável pelo baixo êxito eleitoral das mulheres. Não se pode minimizar o fato de que o aumento do número de candidatas, teoricamente, aumenta as chances, mas de forma alguma garante sozinho maior número de eleitas. O que se observa, de forma diversa, é que, mesmo sem o cumprimento da lei, um expressivo número de candidatas, que gira em torno de $50 \%$ para os dois legislativos em pauta, esteve nas listas apenas para constar, não participando efetivamente da campanha ou recebendo um número insignificante de votos.

Um segundo ponto a ser observado diz respeito à pouca renovação das mulheres eleitas e a presença de carreiras políticas solidificadas entre as eleitas e entre as que tiveram votações expressivas. Esta é uma questão particularmente importante, até porque na comparação com os deputados homens há, entre eles, mais novatos na carreira política. Portanto, ao contrário de um senso comum que associa a vida pública da mulher à atuação nos movimentos de bairro, clubes de mãe e outras atividades associadas aos movimentos sociais, o que registramos são carreiras políticas muito tradicionais, que na maioria das vezes começam na vereança.

As mulheres que se elegem, portanto, são profissionais da política, com carreiras bem estruturadas e experiências anteriores. Essa condição é tão importante que parece ser mais definidora da vitória do que o montante dos recursos e as aparições no HGPE.

Essas observações nos permitem avançar nos estudos sobre a participação política da mulher no Brasil, tomando em consideração dois aspectos 
importantes: o primeiro refere-se à continuidade do pequeno número de eleitas, o segundo revela uma novidade na eleição destas candidatas: as mulheres eleitas têm carreiras políticas tradicionais, isto é, fazem vida partidária obedecendo à hierarquia até chegar à posição de candidatas viáveis e com potencial eleitoral. A combinação dos dois aspectos destacados - maior reeleição de parlamentares mulheres e escassez de candidaturas femininas viáveis em termos de voto - indica, por um lado, que podemos estar frente a mulheres que exercitam satisfatoriamente seu mandato e que, por outro, são necessários programas mais robustos para garantir presença feminina nas listas partidárias com reais possibilidades de vitória.

\section{Referências}

ALVARES, Maria Luzia Miranda (2008). "Mulheres brasileiras em tempo de competição eleitoral: seleção de candidaturas e degraus de acesso aos cargos parlamentares”. Dados, v. 51, n. 4, p. 895-940.

ARAÚJO, Clara (2005). "Partidos políticos e gênero: mediações nas rotas de ingresso das mulheres na representação política”. Revista Sociologia e Política, n. 24, p. 193-215.

(2009). "Gênero e acesso ao poder legislativo no Brasil: as cotas entre as instituições e a cultura”. Revista Brasileira de Ciência Política, n. 2, p. 23-59.

(2011). "Potencialidades e limites da política de cotas no Brasil". Revista Estudos Feministas, v. 9, n. 1, p. 231-252.

AVELAR, Lúcia (2001). Mulheres na elite política brasileira: canais de acesso ao poder. São Paulo: Fundação Konrad Adenauer.

CLIC RBS (2010a). Especial Eleições. Disponível em: www.clibrbs.com.br/ especial/rs/eleições. Acessado em 10 abr 2011.

CLIC RBS (2010b). "Emília Fernandes é a deputada federal mais votada em Livramento". Disponível em http://wp.clicrbs.com.br/livramento/2010/10/03/emilia-fernandes-e-a-deputada-federal-mais-votada-emlivramento/. Acessado em 12 mar 2011.

HORÁRIO GRATUITO DE PROPAGANDA ELEITORAL (HGPE) (2010). Propaganda veiculada na televisão no período de 17 de agosto a 30 de setembro no horário noturno.

FRASER, Nancy (2001). "Da redistribuição ao reconhecimento? Dilemas da Justiça na era pós-socialista”, em SOUZA, Jesse (org.) Democracia 
hoje: novos desafios para a teoria democrática contemporânea. Brasília: Editora UnB.

(2003). "Social justice in the age of identity politics: redistribution, recognition and participation", em FRASER, Nancy \& HONNETH, Axel. Redistribution or recognition? A political-philosophical exchange. London: Verso.

MIGUEL, Luis Felipe (2000). “Teoria política feminista e liberalismo: o caso das cotas de representação". Revista Brasileira de Ciências Sociais, v. 15, n. 44 , p. $91-102$.

(2001). "Política de interesses, política do desvelo: representação e 'singularidade feminina”'. Revista Estudos Feministas, n. 1, p. 253-267. MIGUEL, Luis Felipe \& BIROLI, Flávia (2010). "Práticas de gênero e carreiras políticas: vertentes explicativas”. Revista Estudos Feministas, v. 18, n. 3, p. 653-679.

MULHERES NO PODER (s/d). Disponível em: www.mulheresnopoder. com.br. Acessado em 20 mar 2011.

NICOLAU, Jairo (2006). "Voto personalizado e reforma eleitoral no Brasil", em SOARES, Gláucio A. D. \& RENNÓ, Lúcio (orgs.). Reforma política: lições da história recente. Rio de Janeiro: Editora FGV.

(2007). “O sistema eleitoral de lista aberta no Brasil”, em NICOLAU, Jairo \& POWER, Timothy (orgs.). Instituições representativas no Brasil: balanço e reforma. Belo Horizonte: Editora UFMG.

OBSERVATÓRIO BRASIL DA IGUALDADE DE GÊNERO (s/d). Site. Disponível em: www.observatóriodegenero.gov.br. Acessado em 20 mar 2011.

PINTO, Céli \& MORITZ, Maria Lúcia (2008). "A tímida presença da mulher na política brasileira: eleições municipais em Porto Alegre”. Revista Brasileira de Ciência Política, n. 2, p. 61-87.

TRIBUNAL REGIONAL ELEITORAL - RS (TRE/RS). Site. Disponível em: http://www.tre.gov.br. Acessado em 12 mar 2011.

TRIBUNAL SUPERIOR ELEITORAL (TSE). Site. Disponível em: http://www.tse.gov.br. Acessado em 15 mar 2011.

UNIÃO INTERPARLAMENTAR (ONU). Site. Disponível em: www.ipu. org. Acessado em 01 abr 2012. 


\section{Resumo}

Este artigo objetiva contribuir para o avanço no entendimento do precário desempenho das mulheres nas eleições legislativas no Brasil, a partir do estudo da sua performance na disputa por cargos na deputação estadual e federal no estado do Rio Grande do Sul em 2010. O artigo está divido em duas partes: na primeira apresentaremos uma visão geral das candidaturas femininas no Brasil; na segunda, analisaremos em detalhes o desempenho das candidatas do Rio Grande do Sul à Assembleia Legislativa e à Câmara dos Deputados. Nas conclusões foi constatado um aumento no número de candidaturas femininas. Entretanto, a maior oferta de candidatas não se transformou em mais mulheres eleitas. Aquelas que se elegem possuem uma trajetória política bastante tradicional, nos mesmos moldes do que acontece nos países de democracias maduras.

Palavras-chave: Eleições legislativas 2010; candidaturas femininas; Rio Grande do Sul.

\section{Abstract}

This article aims to contribute to a better understanding of women's weak performance in legislative elections in Brazil by studying their electoral performances to the National Congress and Legislative Assembly (parliament) in the state of Rio Grande do Sul/2010. The article is divided in two parts. The first part presents an overview of female candidates in Brazil. The second one analyses in detail the electoral performance of female candidates in the state to the National Congress and Legislative Assembly. In conclusion, it finds an increase in the number of female candidates. However, this increased number of female candidacies does not convert into more women being elected. The women elected have a fairly traditional political path, in the same way of well-established democracies.

Keywords: legislative elections 2010; female candidacies; Rio Grande do Sul.

Recebido em 30 de maio de 2012.

Aprovado em 19 de novembro de 2012. 